\title{
Attitudes of patients with spondylarthritis or rheumatoid arthritis regarding biological treatment during COVID-19 pandemic: A multi-center, phone-based, cross-sectional study
}

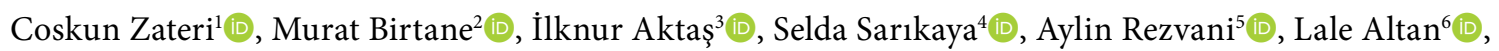

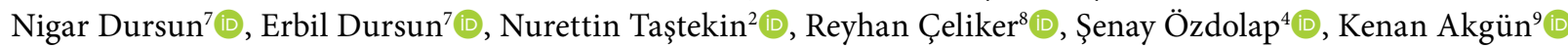

${ }^{1}$ Department of Physical Medicine and Rehabilitation, Çanakkale Onsekiz Mart University, Faculty of Medicine, Çanakkale, Turkey

${ }^{2}$ Department of Physical Medicine and Rehabilitation, Trakya University, Faculty of Medicine, Edirne, Turkey

${ }^{3}$ Department of Physical Medicine and Rehabilitation, Health Sciences University,

Fatih Sultan Mehmet Training and Research Hospital, Istanbul, Turkey

${ }^{4}$ Department of Physical Medicine and Rehabilitation, Bülent Ecevit University, Faculty of Medicine, Zonguldak, Turkey

${ }^{5}$ Department of Physical Medicine and Rehabilitation, Medipol University, International Faculty of Medicine, Istanbul, Turkey

${ }^{6}$ Department of Physical Medicine and Rehabilitation, Uludag University, Faculty of Medicine, Bursa, Turkey

${ }^{7}$ Department of Physical Medicine and Rehabilitation, Kocaeli University, Faculty of Medicine, Kocaeli, Turkey

${ }^{8}$ Department of Physical Medicine and Rehabilitation, Acıbadem University, Faculty of Medicine, Istanbul, Turkey

${ }^{9}$ Department of Physical Medicine and Rehabilitation, Istanbul University, Cerrahpaşa Faculty of Medicine, Istanbul, Turkey

\begin{abstract}
Objectives: In this study, we aimed to investigate the medical treatment attitudes of patients with spondylarthritis or rheumatoid arthritis (RA) who were using biological drugs during the novel coronavirus-2019 (COVID-19) pandemic.

Patients and methods: In this multi-center, cross-sectional study, a total of 277 patients (178 males, 99 females; median age: 45 years; range, 20 to 77 years) who were using biological disease-modifying anti-rheumatic drugs (bDMARDs) for rheumatic diseases and were reached by phone between June $1^{\text {st }}, 2020$ and June $30^{\text {th }}, 2020$ were included. Demographic characteristics, working status, type of the rheumatic disease, comorbidities, smoking habits, and type of the bDMARDs were recorded. Disease activity was evaluated using the Visual Analog Scale (VAS). The patients were asked whether they continued the treatment plan, as it was before or changed and, if changed, how they changed the plan and what happened after the change.

Results: Of the patients, 229 had spondylarthritis and 48 had RA. A total of $36.1 \%$ of the patients were smokers, and the most common comorbidity was hypertension (17.3\%). Totally, $5.8 \%$ of the patients had a history of contact with a COVID-19 positive person. Only three (1.1\%) patients were diagnosed with COVID-19 infection and none of them died. Of the patients, $64.3 \%$ continued their treatment, while $35.7 \%$ adopted various changes. Most patients made the decision about the treatment plan on their own $(n=160,57.8 \%)$, while $38.3 \%$ of them consulted their physicians and $13.9 \%$ of them consulted any health staff. The only significant parameter for changing the drug course was receiving intravenous bDMARDs (by infusion at hospital) $(p=0.001)$. These patients had also a higher disease activity as measured by VAS, compared to the patients receiving non-infusion therapy $(p=0.021)$. As a result of these changes, severity of the symptoms increased in $91(32.9 \%)$ patients. Disruption of regular biological treatment and prior infusion therapy more likely worsened the complaints ( $p<0.001$ and $p=0.024$, respectively).

Conclusion: Intravenous bDMARD therapy seems to be the main factor affecting the continuity of the treatment in the pandemic period. During the pandemic period, alternative treatment options should be considered other than infusion therapy not to interrupt the treatment of these patients. Keywords: Biological therapy, COVID-19, pandemic, rheumatoid arthritis, spondylarthritis.
\end{abstract}

Received: August 03, 2020 Accepted: January 18, 2021 Published online: June 24, 2021

Correspondence: Coşkun Zateri, MD. Çanakkale Onsekiz Mart Üniversitesi Tıp Fakültesi Fiziksel Tıp ve Rehabilitasyon Anabilim Dalı, 17020 Çanakkale, Türkiye. Tel: +90 533 - 5677462 e-mail: zateri@yahoo.com

Citation:

Zateri C, Birtane M, Aktaş I, Sarıkaya S, Rezvani A, Altan L, et al. Attitudes of patients with spondylarthritis or rheumatoid arthritis regarding biological treatment during COVID-19 pandemic: A multi-center, phone-based, cross-sectional study. Arch Rheumatol 2021;36(4):473-481. 
It is a well-known fact that patients with systemic rheumatic diseases using biological disease-modifying anti-rheumatic drugs (bDMARDs) are under risk of severe infections. The outbreak of novel coronavirus-2019 (COVID-19) caused by severe acute respiratory syndrome-coronavirus 2 (SARS-CoV-2) has raised a concern among rheumatologists and patients for the use of such immunosuppressive agents. Since the beginning of 2020, this has been a new dilemma about the effective and safe treatment for rheumatoid arthritis (RA) and spondylarthritis patients with bDMARDs.

After the identification of the first COVID-19 case formally on March $11^{\text {th }}, 2020$ in Turkey, the government issued several restrictions to prevent the spread of the virus. ${ }^{1}$ The consequent lockdown for individuals with chronic diseases also affected patients with rheumatic diseases and they could not apply to the outpatient rheumatology clinics of hospitals which most of them became pandemic facilities restricting elective procedures to serve for COVID-19 patients. The government extended the valid periods of medical reports and, therefore, the patients could continue their medical treatment.

The obligatory lack of face-to-face contact between physicians and patients caused concerns on both sides and this appropriateness was attempted to be overcome through phone calls and internet media communications for some patients, but not for all. In addition to the lack of communication, the individual rheumatologists had different ideas, gave different recommendations for the biological drug course, some of them continued and some of them stopped or tapered according to the individual characteristics of patients or as a standard procedure. ${ }^{2}$ Official national and international professional societies published timely recommendations for the starting or continual process of bDMARDs, most of them were not supported by gross evidence at the beginning of the outbreak of pandemic. ${ }^{3,4}$ All of these uncertainties and lack of communication might have caused different physician and patient attitudes on the maintenance of bDMARD treatment for three-month formally-urged lockdown.

In the present study, we aimed to investigate the medical treatment attitudes of patients with spondylarthritis or RA who were using biological drugs and the major events related to COVID-19 pandemic during the three-month lockdown, until the restrictions resolved formally.

\section{PATIENTS AND METHODS}

This multi-center, cross-sectional study was carried out, rheumatology outpatient clinics of physical medicine and rehabilitation from eight centers between June $1^{\text {st }}, 2020$ and June $30^{\text {th }}, 2020$. Prior to study, all participants were informed about the nature of the study. The study protocol was based on the Zonguldak Bülent Ecevit University, Non-interventional Clinical Trials Ethics Committee (No. 2020/12). The study was conducted in accordance with the principles of the Declaration of Helsinki.

The study population was determined using purposive sampling method, one of the sampling methods with unknown probability. Accordingly, the patients who could be reached between the study period in eight centers and received biological therapy were included. The patients with spondylarthritis or RA who were using bDMARD monotherapy or combined therapy with a conventional synthetic DMARD (csDMARD) until the beginning of COVID-19 restrictions were the foci of the investigation. The physicians in each clinic called the patients they followed by phone and asked standard questions from a standard questionnaire prepared by the authors to the accessible ones. This questionnaire had three main parts. The first part questioned the general pre-COVID status of the patients including demographic characteristics such as age, sex, and working status; type of the rheumatic disease (RA or spondylarthritis); individual characteristics such as comorbidities and smoking habits; and treatment plans applied, such as the use of a tumor necrosis factor (TNF) inhibitor, a non-TNF biological agent, a targeted synthetic DMARD (tsDMARD), and treatment duration. The second part of the questionnaire included questions about the general status and attitudes of the patients during the COVID-restriction period which lasted for three months. In this section, the patients were asked whether they had a COVID-19infected contact, they had COVID-19 infection and, if so, where they were treated, whether they 
were quarantined after contact with an infected person or with suspicion of the infection. The patients were also asked whether they went out for work during the pandemic restrictions; if not, what the reason was. In the third and the last part of the questionnaire, the patients were asked specific questions about the medical biological treatment attitudes during pandemic restriction. These questions examined whether the patients continued treatment plans, as it was before or changed; if so, how they changed the plan and what happened after the change. The answers to the question regarding the treatment plan change were categorized as follows: decided themselves or consulted their rheumatologist or consulted other health staff (a pharmacist, nurse or non-rheumatologist physician). The answers to the question about what happened after the treatment plan change was categorized as follows: complaints worsened, or complaints decreased, or complaints remained unchanged.

Disease activity was evaluated with a global health assessment using Visual Analog Scale (VAS), since physical examination of the cases and laboratory measurements could not be performed. The following question was asked to determine the disease activity of the patients: "Currently, how does your arthritis as a whole affect your life?" The patient was asked to specify a value between 0 and 100, ranging from "Not at all" (0 $\mathrm{mm})$ to "Unbearably much" (100 mm).

\section{Statistical analysis}

Study power analysis and sample size calculation were performed using the G*Power version 3.1 software (Heinrich-Heine-Universität Düsseldorf, Düsseldorf, Germany). The effect size obtained as a result of chi-square analysis was calculated as 0.495 . The beta and alpha error margin was taken as 0.05 . When all these values are formulated, the power of our study is calculated as 0.98 .

Statistical analysis was performed using the IBM SPSS for Windows version 19.0 software (IBM Corp., Armonk, NY, USA). The suitability of numerical variables to normal distribution was evaluated by the Shapiro-Wilk test. Continuous variables were expressed in median (min-max) values, while categorical variables were expressed in number and frequency. Depending on the variable properties, the relationship between the variables was examined using the chi-square, Mann-Whitney U, or Kruskal-Wallis tests. Bonferroni correction was made for statistically significant $p$ values in the chi-square test in multiple comparisons. A $p$ value of $<0.05$ was considered statistically significant.

\section{RESULTS}

Of all 277 patients included in the study of whom most were lost to follow-up during the three-month lockdown, 229 (82.7\%) had spondylarthritis and 48 (17.3\%) had RA. One hundred patients were active smokers and the most common comorbidity was hypertension with $17.3 \%$ of the patients. Of the patients, 247 (89.2\%) were using a TNF inhibitor before the pandemics, while 30 (10.8\%) were on therapy with other bDMARDs. Approximately 20\% of the patients were receiving these drugs by intravenous infusion at the hospital. All these pre-COVID features which constitute the first part of the questionnaire are shown in Table 1.

During three months of social COVID-19 restrictions, 16 (5.8\%) patients had a history of contact with COVID-19-infected patients. Three patients (1.1\%) were diagnosed with COVID-19 infection and none of them died. Two patients were hospitalized, and one was quarantined at home. Quarantine due to pandemic was applied to $10(3.6 \%)$ patients. A total of 165 patients had to go out for work, while 109 were unable to go to work due to restrictions (Table 2).

The major finding about the biological medication course during the three-month restriction period with unhealthy communication between the patient and the rheumatologist was that 178 (64.3\%) patients continued medication plan as it was before, while 22 patients stopped only biological agents, 38 patients decreased or skipped the dose and 39 patients stopped all the biological and non-biological treatments (Table 3). When the factors that affect the patients' decisions regarding continual or modification of biological treatment were questioned, most of them decided themselves ( $n=160,57.8 \%), 106$ (38.3\%) of them consulted their rheumatologist, and 11 (3.9\%) of them consulted other health staff (a pharmacist, nurse, non-rheumatologist physician). As a result of the whole picture, $183(66.1 \%)$ of the patients had unchanged clinical status, while 91 (32.9\%) 


\begin{tabular}{|c|c|c|c|c|}
\hline & $\mathrm{n}$ & $\%$ & Median & Min-Max \\
\hline Age (year) & & & 45 & $20-77$ \\
\hline \multicolumn{5}{|l|}{ Sex } \\
\hline Male & 178 & 64.3 & & \\
\hline Female & 99 & 35.7 & & \\
\hline \multicolumn{5}{|l|}{ Working status } \\
\hline Employed & 165 & 59.6 & & \\
\hline Unemployed & 5 & 1.8 & & \\
\hline Housewife & 58 & 20.9 & & \\
\hline Retired & 49 & 17.7 & & \\
\hline Comorbid disease & 89 & 32.1 & & \\
\hline Hypertension & 48 & 32.1 & & \\
\hline Diabetes mellitus & 17 & 6.1 & & \\
\hline Cardiovascular disease & 15 & 5.4 & & \\
\hline Pulmonary disease & 6 & 2.2 & & \\
\hline Others & 25 & 9.0 & & \\
\hline \multicolumn{5}{|l|}{ Smoking status } \\
\hline Active & 100 & 36.1 & & \\
\hline Quit & 65 & 23.5 & & \\
\hline Never & 111 & 40.1 & & \\
\hline \multicolumn{5}{|l|}{ Rheumatic diseases } \\
\hline Spondyloarthritis & 229 & 82.7 & & \\
\hline Axial spondyloarthritis & 202 & 88.2 & & \\
\hline Psoriatic arthritis & 23 & 10.0 & & \\
\hline Enteropathic arthritis & 4 & 1.7 & & \\
\hline Rheumatoid arthritis & 48 & 17.3 & & \\
\hline \multicolumn{5}{|l|}{ Medications } \\
\hline Anti-tumor necrosis factor & 247 & 89.2 & & \\
\hline Non-TNF biological DMARDs & 30 & 10.8 & & \\
\hline Receiving infusion therapy & 54 & 19.5 & & \\
\hline
\end{tabular}

patients worsened (Table 3). The most increased complaint was pain $(\mathrm{n}=85,30.7 \%)$. The other complaints were morning stiffness ( $n=7,2.5 \%)$, and joint swelling $(n=3,1.1 \%)$.

Advanced statistical analysis on the probable factor affecting the continual or modification biological treatment showed that most of the parameters such as working status, need to go

Table 2. COVID-19 related general status of the patients during COVID-19-related restriction period $(\mathrm{n}=277)$

\begin{tabular}{lcc}
\hline & $\mathrm{n}$ & $\%$ \\
\hline History of contact with COVID-19 patients & 16 & 5.8 \\
Diagnosed with COVID-19 & 3 & 1.1 \\
Quarantine applied due to pandemic & 10 & 3.6 \\
Need to go out for work & 165 & 59.6 \\
Unable to go to work due to restriction & 109 & 66.0 \\
\hline
\end{tabular}

out for work, comorbid diseases, smoking status, type of the rheumatic disease, type of baseline biological medications or history of contact with COVID 19-infected patients did not have any effect for changing the drug course $(p>0.05)$. The only significant parameter for changing the drug course was receiving intravenous bDMARDs $(p=0.001)$ (Table 4).

Since some of the health institutions we work stopped their outpatient clinics due to the pandemic, the patients could not be contacted face-to-face. Since physical examination and laboratory tests were unable to be performed, disease activity was evaluated with a global health assessment using the VAS. In case of disease activity, the patients who continued their regular medicine course had lower disease activity (median [min to max]: 3 [0-10]) according to the VAS than the ones who 
Table 3. Nature and results of altered biological treatment course during COVID-19-related restriction period ( $\mathrm{n}=277)$

\begin{tabular}{|c|c|c|c|}
\hline & $\mathrm{n}$ & $\%$ & Mean \pm SD \\
\hline \multicolumn{4}{|l|}{ Continued medications } \\
\hline Continued as it was before & 178 & 64.3 & \\
\hline Stopped only biological and synthetic therapy & 22 & 7.9 & \\
\hline Decreased or skipped the dose of biological therapy & 38 & 13.7 & \\
\hline Stopped all of the medications & 39 & 14.1 & \\
\hline Disease activity* (Visual Analog Scale) & & & $4.4 \pm 2.8$ \\
\hline \multicolumn{4}{|l|}{ Complaints after treatment changes } \\
\hline Worsened & 91 & 32.9 & \\
\hline Decreased & 3 & 1.1 & \\
\hline Unchanged & 183 & 66.1 & \\
\hline
\end{tabular}

SD: Standard deviation; * Disease activity was evaluated with a global health assessment using Visual Analog Scale, since physical examination of the cases and laboratory measurements could not be performed.

Table 4. Analysis of factors affecting biological treatment process

\begin{tabular}{|c|c|c|c|c|c|c|c|c|c|}
\hline & \multicolumn{2}{|c|}{$\begin{array}{l}\text { Continued as it } \\
\text { was before }\end{array}$} & \multicolumn{2}{|c|}{$\begin{array}{l}\text { Stopped all of the } \\
\text { medications }\end{array}$} & \multicolumn{2}{|c|}{$\begin{array}{c}\text { Stopped only } \\
\text { biological and } \\
\text { synthetic therapy }\end{array}$} & \multicolumn{2}{|c|}{$\begin{array}{l}\text { Decreased or } \\
\text { skipped the dose of } \\
\text { biological therapy }\end{array}$} & \multirow[b]{2}{*}{$p$} \\
\hline & $\mathrm{n}$ & $\%$ & $\mathrm{n}$ & $\%$ & $\mathrm{n}$ & $\%$ & $\mathrm{n}$ & $\%$ & \\
\hline $\begin{array}{l}\text { Working status } \\
\text { Employed } \\
\text { Unemployed } \\
\text { Housewife } \\
\text { Retired }\end{array}$ & $\begin{array}{c}104 \\
4 \\
37 \\
33\end{array}$ & $\begin{array}{l}63.8 \\
80.0 \\
68.5 \\
67.3\end{array}$ & $\begin{array}{c}20 \\
0 \\
6 \\
7\end{array}$ & $\begin{array}{c}12.3 \\
0 \\
11.1 \\
14.3\end{array}$ & $\begin{array}{l}15 \\
0 \\
4 \\
3\end{array}$ & $\begin{array}{c}9.2 \\
0 \\
7.4 \\
6.1\end{array}$ & $\begin{array}{l}24(14.7) \\
1(20.0) \\
7(13.0) \\
6(12.2)\end{array}$ & $\begin{array}{l}14.7 \\
20.0 \\
13.0 \\
12.2\end{array}$ & 0.983 \\
\hline $\begin{array}{l}\text { Need to go out for work } \\
\text { Unable to go to work } \\
\text { due to pandemic } \\
\text { Be able to go to work }\end{array}$ & $\begin{array}{l}75 \\
29\end{array}$ & $\begin{array}{l}69.4 \\
52.7\end{array}$ & $\begin{array}{c}13 \\
7\end{array}$ & $\begin{array}{l}12.0 \\
12.7\end{array}$ & $\begin{array}{l}8 \\
7\end{array}$ & $\begin{array}{c}7.4 \\
12.7\end{array}$ & $\begin{array}{l}12(11.1) \\
12(21.8)\end{array}$ & $\begin{array}{l}11.1 \\
21.8\end{array}$ & 0.135 \\
\hline $\begin{array}{l}\text { Comorbid disease } \\
\text { No comorbidity } \\
\text { Hypertension } \\
\text { Diabetes mellitus } \\
\text { Cardiovascular disease } \\
\text { Pulmonary disease }\end{array}$ & $\begin{array}{c}126 \\
32 \\
10 \\
11 \\
3\end{array}$ & $\begin{array}{l}68.9 \\
66.7 \\
58.8 \\
78.6 \\
60.0\end{array}$ & $\begin{array}{c}19 \\
4 \\
3 \\
1 \\
2\end{array}$ & $\begin{array}{c}10.4 \\
8.3 \\
17.6 \\
7.1 \\
40.0\end{array}$ & $\begin{array}{l}11 \\
4 \\
3 \\
2 \\
0\end{array}$ & $\begin{array}{c}6.0 \\
8.3 \\
17.6 \\
14.3 \\
0\end{array}$ & $\begin{array}{c}27 \\
8 \\
1 \\
0 \\
0\end{array}$ & $\begin{array}{c}14.8 \\
16.7 \\
5.9 \\
0 \\
0\end{array}$ & $\begin{array}{l}0.130 \\
0.799 \\
0.326 \\
0.328 \\
0.222\end{array}$ \\
\hline $\begin{array}{l}\text { Smoking status } \\
\text { Active } \\
\text { Quit } \\
\text { Never }\end{array}$ & $\begin{array}{l}66 \\
44 \\
68\end{array}$ & $\begin{array}{l}67.3 \\
68.8 \\
63.0\end{array}$ & $\begin{array}{c}11 \\
8 \\
14\end{array}$ & $\begin{array}{l}11.2 \\
12.5 \\
13.0\end{array}$ & $\begin{array}{c}6 \\
4 \\
12\end{array}$ & $\begin{array}{c}6.1 \\
6.3 \\
11.1\end{array}$ & $\begin{array}{c}15 \\
8 \\
14\end{array}$ & $\begin{array}{l}15.3 \\
12.5 \\
13.0\end{array}$ & 0.855 \\
\hline $\begin{array}{l}\text { Rheumatic diseases } \\
\text { Spondyloarthritis } \\
\text { Rheumatoid arthritis }\end{array}$ & $\begin{array}{l}148 \\
30\end{array}$ & $\begin{array}{l}65.5 \\
66.7\end{array}$ & $\begin{array}{c}31 \\
2\end{array}$ & $\begin{array}{l}13.7 \\
4.4\end{array}$ & $\begin{array}{l}15 \\
7\end{array}$ & $\begin{array}{c}6.6 \\
15.6\end{array}$ & $\begin{array}{c}32 \\
6\end{array}$ & $\begin{array}{l}14.2 \\
13.3\end{array}$ & 0.096 \\
\hline $\begin{array}{l}\text { Medications } \\
\text { Anti-tumor necrosis factor } \\
\text { Non-TNF biological DMARDs }\end{array}$ & $\begin{array}{l}161 \\
17\end{array}$ & $\begin{array}{l}66.8 \\
56.7\end{array}$ & $\begin{array}{c}28 \\
5\end{array}$ & $\begin{array}{l}11.6 \\
16.7\end{array}$ & $\begin{array}{c}19 \\
3\end{array}$ & $\begin{array}{c}7.9 \\
10.0\end{array}$ & $\begin{array}{c}33 \\
5\end{array}$ & $\begin{array}{l}13.7 \\
16.7\end{array}$ & 0.731 \\
\hline $\begin{array}{l}\text { Receiving infusion therapy } \\
\text { Yes } \\
\text { No }\end{array}$ & $\begin{array}{c}24 \\
153\end{array}$ & $\begin{array}{l}44.4 \\
70.8\end{array}$ & $\begin{array}{c}8 \\
25\end{array}$ & $\begin{array}{l}14.8 \\
11.6\end{array}$ & $\begin{array}{c}7 \\
15\end{array}$ & $\begin{array}{c}13.0 \\
6.9\end{array}$ & $\begin{array}{l}15 \\
23\end{array}$ & $\begin{array}{l}27.8 \\
10.6\end{array}$ & $0.001^{*}$ \\
\hline $\begin{array}{l}\text { History of contact with } \\
\text { COVID-19 patients } \\
\text { Yes } \\
\text { No }\end{array}$ & $\begin{array}{c}8 \\
178\end{array}$ & $\begin{array}{l}50.0 \\
66.7\end{array}$ & $\begin{array}{c}5 \\
28\end{array}$ & $\begin{array}{l}31.3 \\
11.0\end{array}$ & $\begin{array}{c}1 \\
21\end{array}$ & $\begin{array}{l}6.3 \\
8.2\end{array}$ & $\begin{array}{c}2 \\
36\end{array}$ & $\begin{array}{l}12.5 \\
14.1\end{array}$ & 0.121 \\
\hline $\begin{array}{l}\text { Diagnosed with COVID-19 } \\
\text { Yes } \\
\text { No }\end{array}$ & $\begin{array}{c}1 \\
177\end{array}$ & $\begin{array}{l}33.3 \\
66.0\end{array}$ & $\begin{array}{c}1 \\
32\end{array}$ & $\begin{array}{l}33.3 \\
11.9\end{array}$ & $\begin{array}{c}1 \\
21\end{array}$ & $\begin{array}{c}33.3 \\
7.8\end{array}$ & $\begin{array}{c}0 \\
38\end{array}$ & $\begin{array}{c}0 \\
14.2\end{array}$ & 0.221 \\
\hline
\end{tabular}


Table 5. Analysis of factors affecting complaints after treatment changes

\begin{tabular}{|c|c|c|c|c|c|c|c|}
\hline & \multicolumn{6}{|c|}{ Complaints after treatment changes } & \multirow[b]{3}{*}{$p$} \\
\hline & \multicolumn{2}{|c|}{ Increased } & \multicolumn{2}{|c|}{ Decreased } & \multicolumn{2}{|c|}{ Unchanged } & \\
\hline & $\mathrm{n}$ & $\%$ & $\mathrm{n}$ & $\%$ & $\mathrm{n}$ & $\%$ & \\
\hline Continued medications-1* & & & & & & & $<0.001$ \\
\hline Yes & 16 & 9.0 & 1 & 0.6 & 161 & 90.4 & \\
\hline No & 75 & 75.8 & 2 & 2.0 & 22 & 22.2 & \\
\hline Continued medications-2* & & & & & & & $<0.001^{\mathrm{a}}$ \\
\hline Continued as it was before & 16 & 9.0 & 1 & 0.6 & 161 & 90.4 & $<0.001^{\text {b }}$ \\
\hline Stopped all of the medications & 31 & 79.5 & 2 & 5.1 & 6 & 15.4 & $<0.001^{\circ}$ \\
\hline Stopped only biological and synthetic therapy & 18 & 81.8 & 0 & 0 & 4 & 18.2 & $1.000^{\mathrm{d}}$ \\
\hline Decreased or skipped the dose of biological therapy & 26 & 68.4 & 0 & 0 & 12 & 31.6 & $\begin{array}{l}1.000^{e} \\
0.993^{f}\end{array}$ \\
\hline Receiving infusion therapy* & & & & & & & 0.024 \\
\hline Yes & 26 & 48.1 & 0 & 0 & 28 & 51.9 & \\
\hline No & 65 & 29.3 & 3 & 1.4 & 154 & 69.4 & \\
\hline \multicolumn{8}{|c|}{ 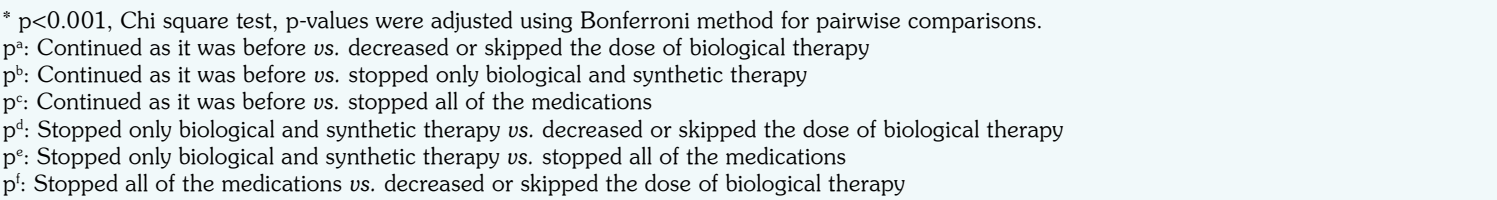 } \\
\hline
\end{tabular}

changed regular plan as expected activity (median [min to max]: 6 [0 to 10]) $(p<0.001)$. The median ( $\mathrm{min}$ to $\max$ ) values for disease activity were 3 (0 to 10$), 7$ ( 1 to 10$), 5.5$ (0 to 10 ), and 6.5 ( 1 to 9) for the patients who continued medication as it was before, who stopped all the medications, who stopped only biological and synthetic therapy, and who decreased or skipped the dose of biological therapy, respectively. This distribution revealed statistically significant differences (continued as it was before vs. decreased or skipped the dose of biological therapy, $\mathrm{p}=0.002$; continued as it was before vs. stopped only biological and synthetic therapy, $p=0.012$, continued as it was before vs. stopped all of the medications, $p<0.001$; stopped only biological and synthetic therapy us. decreased or skipped the dose of biological therapy, $p>0.05$; stopped only biological and synthetic therapy vs. stopped all of the medications, $p>0.05$; and stopped all of the medications $v$ s. decreased or skipped the dose of biological therapy, $p>0.05$. Study patients who received intravenous bDMARD had a higher disease activity, compared to the patients receiving non-infusion therapy (median [min to max]: 5 [0 to 10] vs. 4 [0 to 10], respectively; $\mathrm{p}=0.021$ ).
The trend was almost the same for the change in the complaints. Disruption of regular biological treatment and prior infusion therapy more likely worsened the complaints (Table 5).

\section{DISCUSSION}

In the outbreak of COVID-19, we conducted a cross-sectional study to evaluate the medical treatment behavior of the spondylarthritis and RA patients in our registry and to determine their disease-related status. The COVID-19 pandemic and related lockdown periods had important influence on patients with rheumatic diseases who were receiving bDMARDs. It is not yet known whether the use of a bDMARD increases the risk of COVID-19 infection during the pandemic. While data are growing rapidly, we aimed to share our results about this issue.

Since there is no comprehensive epidemiological research that can represent the society and asymptomatic cases cannot be detected, the frequency of COVID-19 is not known in patients with rheumatic diseases. Obviously, we consider that immunosuppressive therapy increases the risk of severe infections. In our study, 16 (5.8\%) cases had a history of contact with patients with 
COVID-19-suspected or definite diagnosis. The diagnostic tests for COVID-19 were positive in only three cases. The COVID-19 positivity rate was $1.1 \%$. This rate is similar to the rates reported in the literature. Monti et al. ${ }^{5}$ studied in a series of patients with RA and spondylarthritis treated with immunosuppressive targeted therapies and they found COVID-19 positivity in four (1.3\%) of 320 patients. Favalli et al. ${ }^{6}$ investigated the true incidence of COVID-19 in patients with rheumatic diseases. Their study population consisted of 530 patients with RA, psoriatic arthritis, connective tissue diseases, sarcoidosis, or juvenile idiopathic arthritis. In this study, they reported three (0.6\%) COVID-19-positive patients of 530 patients. In a study conducted in Turkey, Seyahi et al. ${ }^{7}$ found four (0.5\%) COVID-19-positive cases among 771 patients with rheumatic diseases. In any of these studies, including our study, the true frequency of COVID-19 in rheumatic diseases cannot be determined. In our study, only the RA and spondylarthritis patients who received biological treatments were included. Of note, our sample is not sufficient to report the actual frequency of all rheumatological patients, as the study population is limited within the described criteria. Since our research was conducted in the northwest Turkey (Istanbul is in this area) where COVID-19 infection was more frequent, we might have detected a higher prevalence rate. In other studies, different rheumatological diseases were also included. ${ }^{[6,7]}$

Some medical societies recommend postponing the start or extending the use of biological therapy, including anti-TNF treatment and recommended the use of interleukin (IL)- 6 inhibitors. ${ }^{3,8}$ Recently, there have been case reports of patients infected with COVID-19 who were using TNF inhibitors. None of the cases died or their clinical pictures worsened due to severe complications. ${ }^{5,9}$ It is even suggested that some drugs used in rheumatological diseases, such as antimalarials, anti-IL-6, antiIL-1, and baricitinib, may be therapeutic in some periods of COVID-19 disease..$^{10}$ Similarly, Brito et al. ${ }^{11}$ indicated that anti-TNF treatment seems to prevent the damaging effects of the high levels of cytokines associated with the immunopathogenesis of infection. However, many patients had the tendency to stop their
bDMARD treatments. In general, the interruption of therapies used in patients with rheumatic disease is not advised. The interruption of the treatment may be responsible for increased complaints and worsened disease course..$^{10}$

The results of the current study showed that 178 (64.3\%) patients continued their treatment as it was before. Ninety-nine (35.7\%) patients either stopped their treatment completely or made various changes in their treatment and they decided to continue or change the treatment mostly on their own $(n=160,57.8 \%)$. Of the patients, 106 (38.3\%) consulted their rheumatologist and 11 (3.9\%) of them consulted other health staff (a pharmacist, nurse, non-rheumatologist physician). Michaud et al. ${ }^{12}$ reported that $14 \%$ of the patients made self-imposed changes to their medication, $11 \%$ of them made physician-directed changes to their medication list or dose, and 10\% of the patients were unable to obtain their medication. López-Medina et al. ${ }^{13}$ conducted in Spain, the rate of making treatment changes was reported as $20.3 \%$. In our study, this rate was $35.7 \%$. The authors emphasized that particularly patients receiving biological therapy made more treatment changes. While $49.2 \%$ of the cases in the same study decided to make a treatment change on their own, this rate was $57.8 \%$ in our study. It was reported that there was fear of getting COVID-19 as the reason for making treatment changes in $63.5 \%$ of the patients. This difference between the studies may have resulted from cultural differences and restrictions due to pandemic.

When the factors that caused changes in medication were analyzed, only patients who received infusion therapy that needed to be administered in the hospital had more statistically significant changes $(p=0.001)$. Other factors such as working status, comorbidity, smoking habits, type of rheumatic disease, anti-TNF, and other bDMARDs, contact with COVID-19 patients and COVID-19 infection had no effect on the change of treatment $(p>0.05)$. The fact that patients with rheumatic disease using immunosuppressive therapy refrained from visiting hospitals to reduce the risk of infection can explain this situation. It is important to facilitate patients' access to medication in such pandemic situations. For this purpose, instead of intravenous bDMARDs, other 
treatment options that one can apply on their own should be considered as much as possible.

As a result of changes in the treatment mentioned above, there was a statistically significant increase in complaints of 91 (32.9\%) patients $(p<0.001)$. The most increased complaint was pain $(n=85,30.7 \%)$. The other complaints were morning stiffness ( $\mathrm{n}=7,2.5 \%)$, and joint swelling ( $n=3,1.1 \%)$. Patients who stopped or changed the treatment reported a higher disease activity, compared to those who used their treatment regularly.

The risk of opportunistic and communityacquired respiratory infections is increased in rheumatic diseases. However, drugs used in the treatment of rheumatic diseases are also thought to contribute to this increased risk. ${ }^{14,15}$ Although no rheumatic disease has yet been reported as a risk factor for COVID-19 infection, it is thought that these patients are among the risky groups in terms of tendency to infection due to the high number of immunosuppressive treatments and comorbid conditions. ${ }^{2,16}$ In a study with the largest COVID-19 case collection among patients with rheumatic disease and 600 cases from 40 countries, hospitalization-related factors due to COVID-19 including older age, comorbidities, and high-dose prednisone ( $\geq 10 \mathrm{mg} /$ day) were identified. However, it is stated that biological/ targeted specific DMARD monotherapy is associated with a lower hospitalization rate and is largely driven by anti-TNF treatments. Over half of the reported cases did not require hospitalization, including patients receiving biological/targeted specific DMARDs. ${ }^{17}$

The COVID-19 outcomes in patients with rheumatic diseases are still poorly understood. Patients with rheumatic diseases need to be followed closely, and individualized therapies may be necessary. However, during the COVID19 pandemic, most outpatient and inpatient clinics were converted to pandemic clinics for COVID-19 patients. Many patients called us about their treatment options during the pandemic period. Based on our experience, we suggest that the patients should be able to get access to their medical professional via phone or other online tools. Rheumatology societies such as the American College of Rheumatology (ACR) and European League Against Rheumatism (EULAR) recommended the use of telemedicine methods in patient follow-up and treatment. ${ }^{3,18}$ Telemedicine services are patient-centered, convenient for the patient to remain in quarantine and protect patients, clinicians and the public from infection exposure. Thanks to the telemedicine services, it is also possible for the healthcare professionals to follow the treatment avoiding face-to-face exposure of infection. ${ }^{14,19}$ These applications can offer patients treatment without disruption and with protection from COVID-19 and similar outbreaks.

The present study has some limitations. First, the cases were questioned by phone only. Since some of the health institutions we work stopped their outpatient clinics due to the pandemic, face-to-face interviews were unable to be performed and the questioning of the patients was limited. Second, the disease activity could not be determined objectively and accurately, since physical and laboratory examinations could not be performed. Instead, disease activity was evaluated with a global health assessment using the VAS. Finally, since our study was a telephone-based questionnaire study, information based on patients' statements could be collected only. However, the statements of the patients may have not reflected their actual situation at all. Nonetheless, it is thought that this may only affect the answers given to the question about disease activity and complaints and not affect the answer to the question regarding the treatment change.

In conclusion, our study showed that 35.7\% of the patients either stopped their treatment completely or made various changes in their treatment plan during the COVID-19 pandemic. Intravenous biological treatment was the most significant parameter affecting this condition. Comparison between those who continued their biological treatment as it was before and those who stopped or decreased/skipped only biological treatment or stopped all medications showed that those who continued treatment fully had fewer complaints. Recently, experience has been increasing on how to use immunosuppressive therapies in rheumatic diseases during the epidemic periods. In rheumatic patients, discontinuation or interruption of treatment is not recommended. Keeping the disease activity under control is as important as the protection of patients from the COVID-19 infection during the pandemic. Further 
clinical trials may helpful to define the benefit of biological therapy and their applicability to reduce the incidence of severe forms of COVID-19 in the real-life setting.

\section{Declaration of conflicting interests}

The authors declared no conflicts of interest with respect to the authorship and/or publication of this article.

\section{Funding}

The authors received no financial support for the research and/or authorship of this article.

\section{REFERENCES}

1. Available at: https://en.wikipedia.org/wiki/COVID19_pandemic_in_Turkey. [Accessed: July 12, 2020].

2 Price E, MacPhie E, Kay L, Lanyon P, Griffiths $B$, Holroyd $C$, et al. Identifying rheumatic disease patients at high risk and requiring shielding during the COVID-19 pandemic. Clin Med (Lond) 2020;20:25661.

3. Mikuls TR, Johnson SR, Fraenkel L, Arasaratnam RJ, Baden LR, Bermas BL, et al. American college of rheumatology guidance for the management of rheumatic disease in adult patients during the COVID-19 pandemic: Version 1. Arthritis Rheumatol 2020;72:1241-51.

4. Landewé RB, Machado PM, Kroon F, Bijlsma HW, Burmester GR, Carmona L, et al. EULAR provisional recommendations for the management of rheumatic and musculoskeletal diseases in the context of SARSCoV-2. Ann Rheum Dis 2020;79:851-8.

5. Monti S, Balduzzi S, Delvino P, Bellis E, Quadrelli VS, Montecucco C. Clinical course of COVID-19 in a series of patients with chronic arthritis treated with immunosuppressive targeted therapies. Ann Rheum Dis 2020;79:667-8.

6. Favalli EG, Ingegnoli F, Cimaz R, Caporali R. What is the true incidence of COVID-19 in patients with rheumatic diseases? Ann Rheum Dis 2021;80:e18.

7. Seyahi E, Poyraz BC, Sut N, Akdogan S, Hamuryudan $\mathrm{V}$. The psychological state and changes in the routine of the patients with rheumatic diseases during the coronavirus disease (COVID-19) outbreak in Turkey: a web-based cross-sectional survey. Rheumatol Int 2020;40:1229-38.

8. ISBD. BD and COVID-19-management advice for clinicians. Available at: http://www. behcetdiseasesociety.org/4/news/9/bd-and-covid-19management-advice-for-clinicians. [Accessed: July 12, 2020].

9. Duret PM, Sebbag E, Mallick A, Gravier S, Spielmann L, Messer L. Recovery from COVID-19 in a patient with spondyloarthritis treated with TNF-alpha inhibitor etanercept. Ann Rheum Dis 2020;79:1251-2

10. Ceribelli A, Motta F, De Santis M, Ansari AA, Ridgway WM, Gershwin ME, et al. Recommendations for coronavirus infection in rheumatic diseases treated with biologic therapy. J Autoimmun 2020;109:102442.

11. Brito CA, Paiva JG, Pimentel FN, Guimarães RS, Moreira MR. COVID-19 in patients with rheumatological diseases treated with anti-TNF. Ann Rheum Dis 2020:annrheumdis-2020-218171.

12. Michaud K, Wipfler K, Shaw Y, Simon TA, Cornish A, England BR, et al. Experiences of patients with rheumatic diseases in the United States during early days of the COVID-19 Pandemic. ACR Open Rheumatol 2020;2:335-43.

13. López-Medina C, Ladehesa-Pineda L, GómezGarcía I, Puche-Larrubia MÁ, Sequí-Sabater JM, Armenteros-Ortiz $\mathrm{P}$, et al. Treatment adherence during the COVID-19 pandemic and the impact of confinement on disease activity and emotional status: A survey in 644 rheumatic patients. Joint Bone Spine 2020;88:105085.

14. Yağcı İ, Bahşi A. Romatizmal hastalıklar ve COVID19. In: Ayhan FF, Demirbağ-Kabayel D, editörler. COVID-19 pandemisi ve Fiziksel Tip ve Rehabilitasyon. 1. Baskı. Ankara: Türkiye Klinikleri; 2020. s. 60-9.

15. Galloway JB, Hyrich KL, Mercer LK, Dixon WG, Fu B, Ustianowski AP, et al. Anti-TNF therapy is associated with an increased risk of serious infections in patients with rheumatoid arthritis especially in the first 6 months of treatment: updated results from the British Society for Rheumatology Biologics Register with special emphasis on risks in the elderly. Rheumatology (Oxford) 2011;50:124-31.

16. Zhang Y, Wang J, Zhao L, Xiao J, Shi Z. Online management of rheumatoid arthritis during COVID19 pandemic. Ann Rheum Dis 2021;80:e4.

17. Gianfrancesco M, Hyrich KL, Al-Adely S, Carmona L, Danila MI, Gossec L, et al. Characteristics associated with hospitalisation for COVID-19 in people with rheumatic disease: data from the COVID-19 Global Rheumatology Alliance physician-reported registry. Ann Rheum Dis 2020;79:859-66.

18. EULAR Guidance for patients COVID-19 outbreak. Available at: https://www.eular.org/eular_guidance _ for_patients_covid19_outbreak.cfm. [Accessed: July 12, 2020].

19. Hollander JE, Carr BG. Virtually perfect? Telemedicine for COVID-19. N Engl J Med 2020;382:1679-81. 